\title{
EL CASTILLO DE VILLANUEVA DE VALDEJAMUZ: UNA CONSTRUCCIÓN DEFENSIVA EN EL MARCO DE LA CONFLICTIVIDAD SOCIAL LEONESA DURANTE LA BAJA EDAD MEDIA
}

\author{
Raquel MARTÍNEZ PEÑÍN \\ Universidad de León
}

Recibido: 20/07/2012

Aceptado: 08/10/2012

RESUMEN: Este artículo se centra en el estudio de la evolución experimentada por las construcciones defensivas de la fortaleza de Villanueva de Jamuz (León) en los momentos finales de la Baja Edad Media e inicios de la Edad Moderna. Para llevar a cabo este trabajo contamos, por un lado, con la información emanada de las recientes intervenciones arqueológicas desarrolladas en la principal puerta de acceso al castillo y, por otro, con los materiales localizados en las mismas.

PALABRAS CLAVE: ortaleza, arqueología medieval, muralla, León, Baja Edad Media.

ABSTRACT: This article focuses on the study of the evolution of defensive constructions of the strength of Villanueva de Jamuz (León) in the final moments of the late Middle Ages and Early Modern period. To accomplish this we work on the one hand, with the information emanating from recent archaeological work carried out in the main gateway to the castle and on the other, with the materials found in them.

KEYWORDS: castle, medieval archeology, wall, León, Late Medieval.

\section{OBJETIVOS Y CONTEXTUALIZACIÓN ESPACIAL Y TEMPORAL}

El presente trabajo se centra en el análisis de una de las fortificaciones de época medieval más emblemáticas de la provincia de León: el castillo de Villanueva de Jamuz $^{1}$. Nuestro objetivo es conocer la evolución experimentada por su sistema defensivo en los momentos finales de la Baja Edad Media e inicios de la Moderna. Estas transformaciones coinciden con la pugna que los Quiñones, señores de

${ }^{1}$ Este trabajo forma parte del proyecto de investigación titulado "Marginación y asistencia social en el Noroeste de la Península Ibérica durante el Antiguo Régimen", subvencionado por el Ministerio de Ciencia e Innovación (Ref. HAR 2010-17780). 
Valdejamuz y promotores de la fortaleza, mantuvieron con la casa condal de Luna por hacerse con el control de esta jurisdicción territorial. Así, trataremos de comprobar si tal confrontación afectó de alguna manera a las construcciones del castillo. Para alcanzar este objetivo contamos con una serie de intervenciones arqueológicas practicadas en el enclave durante los últimos años.

El pueblo de Villanueva de Jamuz se sitúa a unos $58 \mathrm{~km}$. al W. de la ciudad de León y en la actualidad cuenta con una población de aproximadamente 300 habitantes, dedicados en su mayor parte a labores agrícolas y ganaderas (Mapa 1). A lo largo de la Edad Media este pequeño núcleo, al que se le conocía como Villanueva de Simón Sánchez, formaba parte de los territorios que conformaban el señorío de Valdejamuz (Villanueva de Simón Sánchez, Santa Elena, Jiménez, Herreros, Congosto y Quintana de Jamuz).

En el siglo XII, espacio pasa a constituirse como parte del territorio que el linaje de los Vermúdez poseía en el Reino de León y, un siglo después, fue transferido al de los Moranes. Hacia 1370 se integrará en el señorío de los Quiñones de la mano del que fuera Adelantado Mayor de León y de Asturias, Pedro Suárez de Quiñones (1367-1402), donando Villanueva y sus aldeas a su sobrino Diego Fernández de Quiñones, vinculando así Valdejamuz al señorío de los Quiñones durante el resto de la Edad Media ${ }^{2}$.

Tiempo después, el monarca Juan II concede a Diego Fernández de Quiñones la potestad de fundar mayorazgo, que lo hace en las personas de sus cuatro hijos varones. Así, el concejo de Valdejamuz pasa a al segundo de ellos, Suero Quiñones I (1409-1458). Tras la muerte de Suero y aplicando el mayorazgo, Valdejamuz pasa a manos de su hijo Diego Quiñones I (1438-1484). A su vez, este último deja como heredero a su único hijo, de tan solo seis años de edad, Diego Quiñones II (1478-1540).

Ante esta coyuntura desfavorable, el conde de Luna no reconoce a Diego como heredero legítimo de su padre y, a finales del siglo XV, se llevan a cabo una serie de hurtos contra los vecinos de Villanueva ${ }^{3}$. Estas desavenencias derivarán

${ }^{2}$ Merino, W. (1979). «Castillos del Paso Honroso, Laguna de Negrillos y Villanueva de Valdejamuz». Castillos de España, 17, pp. 13-31; Alvarez Álvarez, C. (1982). El condado de Luna en la Baja Edad Media. León: Colegio Universitario de León. Álvarez, C. (1981). «Castillos medievales leoneses de la casa condal de Luna». Estudios Humanísticos, 3, pp. 141-152; ÁlvareZ Álvarez, C. (1997). Los Quiñones, señores de Valdejamuz (1435-1590). Astorga: Centro de Estudios Astorganos "Marcelo Macías".

3 A. G. S. (Archivo General de Simancas), Consejo Real de Castilla, legajos 148607,54; 148608,85 . 
posteriormente en un largo pleito entre la Casa de Luna y los señores de Valdejamuz. La situación finalizará en el año 1590 con la muerte sin descendencia de Suero Quiñones II (1517-1590), de modo que los bienes del mayorazgo pasan íntegramente a los condes de Luna ${ }^{4}$.

A partir de ese momento, y a lo largo de toda la Edad Moderna el concejo de Valdejamuz conforma parte de los dominios de los condes de Luna, hasta que a finales del siglo XIX la abolición del Régimen Señorial suponga la transformación de las formas de organización política y la aparición de un marco administrativo constituido en torno a los ayuntamientos y pedanías. Entonces, Santa Elena de Jamuz se constituirá en cabeza del municipio, mientras que la población de Villanueva de Jamuz pasa a articularse como simple pedanía ${ }^{5}$.

\section{EL CASTILLO DE VILLANUEVA: UNA REVISIÓN HISTORIOGRÁFICA}

El nacimiento del castillo de Villanueva de Valdejamuz debemos encuadrarlo en el contexto de estos enfrentamientos nobiliarios tan comunes durante la Baja Edad Media. Si la Plena Edad Media se caracteriza, fundamentalmente, por la proliferación de fortificaciones de frontera ${ }^{6}$, el número de estas disminuye sustancialmente a finales del siglo XIII tras finalizar buena parte de los conflictos militares que caracterizaron los momentos anteriores. Esta situación se mantiene hasta que surge de forma abierta el enfrentamiento interno entre Pedro I y Enrique de Trastámara. La victoria de este último provoca el rápido ascenso de una nueva nobleza que, progresivamente, adquiere del monarca importantes concesiones territoriales, económicas y derechos jurisdiccionales ${ }^{7}$. Esto se verá ampliamente

4 Álvarez, C. (1981). «Castillos medievales leoneses de la casa condal de Luna». Estudios Humanísticos, 3, pp. 147; Álvarez Álvarez, C. (1997). Los Quiñones, señores de Valdejamuz (1435-1590). Astorga: Centro de Estudios Astorganos "Marcelo Macías", pp. 43.

5 Rubio Pérez, L. M. (1993). El sistema político concejil en la provincia de León. León: Universidad de León, pp. 115.

${ }^{6}$ MARTínez SopenA, P. (1989). «Las pueblas reales de León y la defensa del reino en los siglos XII y XIII». En LADERO, F. (ed.). Castillos Medievales del Reino de León. Madrid: Hullera VascoLeonesa, pp. 113-137.

7 Alvarez Álvarez, C. (1982). El condado de Luna en la Baja Edad Media. León: Colegio Universitario de León. Álvarez, C. (1981). «Castillos medievales leoneses de la casa condal de Luna». Estudios Humanísticos, 3, pp. 141-152; ÁlvareZ ÁlvareZ, C. (1997). Los Quiñones, señores de Valdejamuz (1435-1590). Astorga: Centro de Estudios Astorganos "Marcelo Macías"; ÁlvareZ Álvarez, C. (1999). La Historia de León, Volumen II. Edad Media. León: Universidad de León; Álvarez Álvarez, C. y Martín Fuertes, J. A. (1977). Catálogo del Archivo de los condes de Luna. León: Colegio Universitario de León; GuTIÉRREZ, J. A. (1994). «El castillo de Villanueva de Jamuz (León): Un ejemplo de fortificación innovadora a mediados del siglo XV». Estudios de historia y de arqueología medievales, 10, p. 200. 
reflejado en la erección de una serie de núcleos fortificados y sistemas defensivos de los siglos XIV y XV, construidas además de como residencia y refugio, como el lugar desde el que ejercer el poder jurisdiccional. La mayoría se situarán en el ámbito rural y coinciden con las principales vías de comunicación de la época. Estas construcciones se irán adaptando progresivamente a las transformaciones poliorcéticas de fines de la Edad Media, inicios de la Edad Moderna.

Tal coyuntura hace que proliferen las edificaciones militares en la zona oriental del territorio leonés -los valles Esla, Cea y Valderaduey, el territorio paramés, la Tierra de Campos, etc.-. Buena parte de estas corresponden a núcleo fortificados que cuentan ya con una ocupación anterior -Coyanza, Laguna de Negrillo, Rueda, Toro, Aguilar de Campos, etc.-. Mientras que otros, caso de Villanueva de Valdejamuz, son creados ex novo para ejercer el poder jurisdiccional sobre el territorio circundante.

Parece que, la torre del homenaje del castillo de Villanueva, levantada con piedra local, de planta rectangular y un total de cinco alturas, debió erigirse en tiempos Diego Fernández de Quiñones entre 1415 y 1435, coincidiendo su momento de mayor actividad política ${ }^{8}$. Esta hipótesis la confirmaría la heráldica conservada en sus muros, en donde aparecen los escudos del noble y de su esposa María de Toledo. Además, existe una clara concordancia con sus contemporáneas de Laguna de Negrillos o Quintana del Marco, construidas también por los Quiñones ${ }^{9}$.

8 Álvarez Álvarez, C. (1997). Los Quiñones, señores de Valdejamuz (1435-1590). Astorga: Centro de Estudios Astorganos "Marcelo Macías", p. 35.

9 CoOPER, E. (1980). Castillos Señoriales de Castilla s. XV y XVI. Madrid: Fundación Universitaria Española, p. 406; COOPER, E. (1991). Castillos señoriales en la Corona de Castilla. Valladolid: Consejería de Cultura y Turismo de la Junta de Castilla y León, pp. 299-300; GuTIÉRREZ, J. A. y BENÉITEZ, C. (1997). «Aportaciones al repertorio cerámico bajomedieval castellano: las producciones de Valencia de don Juan». La céramique médiévale en Méditerraneé. Actes du 6 congrés, Aix-en-Provence. Aix-en-Provence: Narration Éditions, pp. 539-548; CoBos GuERRA, F. y RETUERCE Velasco, M. (2011). Metodología, valoración y criterios de intervención en la arquitectura fortificada de Castilla y León. Cátalogo de las provincias de León, Salamanca, Valladolid y Zamora. Valladolid: Junta de Castilla y León, Consejería de Cultura y Turismo; GuTIÉRREZ, J. A. (1989). «Arquitectura militar y sistemas de fortificaciones en el Reino de León». En Ladero Quesada, F. (ed.). Castillos Medievales del Reino de León. Madrid: Sociedad Hullera Vasco-Leonesa, pp. 157-173; GuTIÉRREZ, J. A. (1992). «Castillos y sistemas de defensa en los reinos de León y Castilla». En Iglesia DuARTE, I. (ed.). II ${ }^{a}$ Semana de Estudios Medievales Instituto de Estudios Riojanos. Nájera: Instituto de Estudios Riojanos, pp. 31-48; GutiérREZ GonZÁLEZ, J. A. (1995). Fortificaciones y feudalismo en el Origen y Formación del Reino de León. Valladolid: Universidad de Valladolid; GuTIÉRREZ, J. A. (1996): «Castillos y fortificaciones en León durante la 
Por su parte, la construcción de la muralla se encuadra en vida de Suero Quiñones I (1409-1458). Esta última posee planta trapezoidal y se adosa a la torre del homenaje por su esquina noroeste. El restos de los ángulos del recinto murario de rematan con cubos de planta cuasi circular. En paralelo al paño meridional se construye un antemuro conservado en parte. También en esos momentos, se erige la puerta principal de acceso al castillo en el centro del lienzo oriental y se hace a base de otro cubo peraltado ${ }^{10}$.

Desde el punto de vista historiográfico, una de las primeras referencias al castillo de Villanueva de Jamuz corresponde a Gómez Moreno ${ }^{11}$, que habla de las semejanzas constructivas que éste tiene con la fortaleza de Laguna de Negrillos. Este erudito sugiere que la muralla primitiva que circundaba a la fortaleza podría haber sido de tapial, contando a su vez con un arco apuntado de ladrillo en medio del lienzo este, para, en tiempos de Hernández de Quiñones, proceder a levantar la torre del homenaje. Lo que se encuentra Gómez Moreno es una torre vacía al interior, en la que identifica hasta cuatro alturas, incluida una entrada en el primer piso. Esta línea descriptiva es la que siguen posteriormente autores como Domínguez Berrueta $^{12}$, Pastrana García $^{13}$ o Marcos Segovia ${ }^{14}$.

Por otro lado, Cooper sostiene que estamos ante una construcción inspirada en los modelos de castillos franceses de los siglos anteriores, aunque con ligeras variaciones. Al igual que Gómez Moreno, emparenta la fortaleza de Villanueva con la de Laguna de Negrillos, construido también por los Quiñones, relacionando su ejecución con el mismo maestro de obra ${ }^{15}$.

Por otro lado, el trabajo de Gutiérrez González se centra en el análisis arquitectónico de la fortaleza, limitándose a describe las construcciones que se

Edad Media». En Arqueoleón. Historia de León a través de la Arqueología. León: Junta de Castilla y León, Instituto Leonés de Cultura, pp. 163-170.

10 GutiérReZ, J. A. (1994). «El castillo de Villanueva de Jamuz (León): Un ejemplo de fortificación innovadora a mediados del siglo XV». Estudios de historia y de arqueología medievales, 10 , p. 200-205.

${ }^{11}$ Gómez Moreno, M. (1925). Catálogo Monumental de la provincia de León. León: Ediciones Nebrija, pp. 465-467.

12 Domínguez Berrueta, M. D. (1979): Castillos de León. Ediciones Nebrija, León, pp. 64-66.

${ }^{13}$ Pastrana García, J. (1979). León, ermitas y castillos. León: Pastrana, D. L, pp. 120-123.

${ }^{14}$ Marcos De Segovia, M. (1954): «Castillos bañezanos». Boletín de la Asociación Española de Amigos de los Castillos, 6, pp. 233-247.

15 CoOper, E. (1980). Castillos Señoriales de Castilla s. XV y XVI. Madrid: Fundación Universitaria Española, p. 406; COOPER, E. (1991). Castillos señoriales en la Corona de Castilla. Valladolid: Consejería de Cultura y Turismo de la Junta de Castilla y León, pp. 299-300. 
conservan en pie: la torre del homenaje, la muralla o su acceso principal. Al respecto, hemos de tener en cuenta que, en los momentos en los que el autor realiza este artículo, no se había llevado a cabo ninguna excavación arqueológica en el sitio $^{16}$.

Los estudios referidos al contexto histórico en el que se lleva a cabo la construcción del castillo de Villanueva de Jamuz son obra, en primer lugar, de Merino Rubio con su trabajo sobre patrimonio de los Quiñones ${ }^{17}$. Pero, sobre todo, destacan la monografía que Álvarez Álvarez dedica al señorío de Valdejamuz ${ }^{18}$.

Desde el punto de vista arqueológico, debemos mencionar los artículos que Cortés dedica a los trabajos de campo efectuados en la torre del homenaje durante el año $2001^{19}$.

Finalmente, ha visto la luz un breve catálogo sobre fortificaciones de Castilla y León en el que se incluye una muy breve descripción de las características edilicias del castillo ${ }^{20}$.

\section{ANTERIORES EXCAVACIONES ARQUEOLÓGICAS EN EL CASTILLO}

En los trabajos arqueológicos llevados a cabo en el año 2001 se excavaron dos sondeos. El primero se realizó al interior de la torre del homenaje, en su esquina sureste, y midió $2,2 \mathrm{~m}$. por 1,5 m. Las labores de campo depararon la localización de un vano tapiado en el lienzo meridional que presumiblemente permitía el acceso desde la torre a la muralla. También se reconoció parte de la pared de tapial del recinto primigenio dado que se encuentra cortada por la zanja de cimentación del

16 GutiérRez, J. A. (1994). «El castillo de Villanueva de Jamuz (León): Un ejemplo de fortificación innovadora a mediados del siglo XV». Estudios de historia y de arqueología medievales, 10, pp. 199-233.

${ }_{17}$ Merino, W. (1979). «Castillos del Paso Honroso, Laguna de Negrillos y Villanueva de Valdejamuz». Castillos de España, 17, pp. 13-31.

18 Álvarez Álvarez, C. (1997). Los Quiñones, señores de Valdejamuz (1435-1590). Astorga: Centro de Estudios Astorganos "Marcelo Macías".

${ }^{19}$ CORTÉs, J. L. (2005). «Intervención arqueológica en el castillo de Villanueva de Jamuz». Lancia, 6, pp. 274-283; CORTÉs, J. L. (2006). «Intervención arqueológica en el castillo de Villanueva de Jamuz». Castillos de España, 144, pp. 23-30.

${ }^{20}$ Cobos Guerra, F. y Retuerce Velasco, M. (2011). Metodología, valoración y criterios de intervención en la arquitectura fortificada de Castilla y León. Cátalogo de las provincias de León, Salamanca, Valladolid y Zamora. Valladolid: Junta de Castilla y León, Consejería de Cultura y Turismo, pp. 106, 136. 
muro de la torre. Además, Cortés Santos identificó los restos de dos posibles pavimentos, apoyados en la mencionada estructura de tapial ${ }^{21}$.

El segundo, de 1,5 m. de ancho, se desarrolló en la base de la torre del homenaje, donde se exhumaron una serie de construcciones posteriores a la torre. Se identificó parte de la secuencia estratigráfica del patio y una posible crujía adherida al lienzo este de la torre, que fue erigido sobre otras construcciones previas asentadas directamente sobre el sustrato natural. Finalmente se localizó también lo que parece ser un pequeño tramo de la muralla de tapia.

Con el objetivo de rehabilitar la muralla y acondicionar el interior de la torre del homenaje como vivienda, la arqueóloga González Fernández vuelve a intervenir al interior del castillo unos años más tarde. A lo largo de esta campaña se llevó a cabo, por un lado, el vaciado del cubo noroeste de la muralla y, por otro, la limpieza del suelo del patio interior, localizándose una superficie de lajas que se extiende por gran parte del mismo. También se excavó un pequeño sondeo, de $6 \mathrm{~m}$. de largo por $2 \mathrm{~m}$. de ancho, emplazado frente al pasillo abovedado que comunica la puerta principal de acceso con el patio interior, exhumándose aquí parte de una atarjea que se terminó de sacar a la luz en la intervenciones que nos ocupa ${ }^{22}$.

En el año 2009, con motivo de las obras de acondicionamiento del entorno del castillo de Villanueva de Jamuz que se plantearon desde el Excmo. Ayuntamiento de Santa Elena de Jamuz, se acometió una nueva excavación arqueológica al exterior del mismo ${ }^{23}$. Así, se plantearon dos sondeos de $39 \mathrm{~m}^{2}$, repartidos en dos zonas. La primera se practicó en el lateral este del castillo, de $7 \mathrm{~m}$. de largo por 3 $\mathrm{m}$. de ancho. Mientras que el segundo, con $6 \mathrm{~m}$. de longitud por $3 \mathrm{~m}$. de anchura, se lleva a cabo en el lateral norte del mismo. El primero permitió localizar el foso del castillo, así como la berma, de unos 4,5 m. de anchura, desde la que arrancaba. En el segundo se pudo identificar también, aunque en este caso surge desde el pie de la misma muralla de la fortaleza.

${ }^{21}$ CoRTÉs, J. L. (2006). «Intervención arqueológica en el castillo de Villanueva de Jamuz». Castillos de España, 144, pp. 23-30.

22 GONZÁLEZ FERNÁNDEZ, M ${ }^{\mathrm{a}}$ L. (2004). Excavación, seguimiento y/o documentación arqueológica en las obras de rehabilitación parcial del castillo de Villanueva de Jamuz. León: Informe inédito depositado en el Servicio Territorial de Cultura de León, Junta de Castilla y León.

${ }^{23}$ San Román Fernández, F, Campomanes Alvaredo, E. y Muñoz Villarejo, F. (2009). Informe preliminar excavación arqueológico castillo de Villanueva de Jamuz, Santa Elena de Jamuz (León). León: Informe inédito depositado en el Servicio Territorial de Cultura de León, Junta de Castilla y León. 


\section{LA RECIENTE INTERVENCIÓN ARQUEOLÓGICA EN LA FORTA- LEZA}

Los trabajos de campo depararon la localización de una serie de elementos constructivos, de carácter defensivo, cuya cronología se extiende desde la Baja Edad Media hasta los inicios de la Edad Moderna.

El castillo se ubica en la localidad de Villanueva de Jamuz, población que forma parte del municipio leonés de Santa Elena de Jamuz (Mapa 1). La fortificación se emplaza en plena entrada del pueblo y sus Coordenadas Geográficas son $42^{\circ} 13^{\prime}$ $58^{\prime \prime}$ Lat. N, $02^{\circ} 10^{\prime} 10^{\prime \prime}$ Long. O, mientras que las UTM: X 264.123.11, Y 4.679.559.62.

$\mathrm{Al}$ respecto, hemos de tener en cuenta que el enclave se encuentra bajo la declaración genérica de Bien de Interés, Decreto de 22 de abril de 1949, y la ley 16/1985 sobre el Patrimonio Histórico Español, por lo que goza, tal y como recogen las normas urbanísticas municipales, de una "protección integral". De hecho, el Ayuntamiento de Santa Elena de Jamuz planteó, hace un tiempo, en este espacio una serie de obras destinadas a mejorar el entorno del la fortaleza. El espacio incluido en dicho proyecto se ubicada al exterior del lienzo oriental del recinto amurallado, pero sobre todo a la puerta principal. Esto motivó que se llevara a cabo la excavación arqueológica de la mencionada área de acceso, con el objetivo de poder conocer el estado y la extensión de estas construcciones, así como la preservación de los restos.

En un primer momento el sondeo se proyectó con unas medidas de $2,5 \mathrm{~m}$. de anchura por $9 \mathrm{~m}$. de largo. Sin embargo, debido a la entidad de las construcciones localizadas, se amplió hasta llegar a excavar cerca de $32 \mathrm{~m}^{2}$, con un potencial estratigráfico de aproximadamente $2 \mathrm{~m}$.

La campaña de excavación comenzó con los trabajos de limpieza y desbroce practicadas en el área situada al exterior del lienzo oriental del castillo, con la finalidad de dejar el terreno lo más horizontal y despejado posible. Así, se planteó un único sondeo, paralelo a la línea de la muralla, justo en frente de la puerta de acceso a la fortaleza, donde afloraban ya en superficie restos visibles de alguna construcción.

El sondeo presentaba una orientación norte-sur, teniendo, en principio, unas medidas de 2,5 m. de ancho por $9 \mathrm{~m}$. de largo (Foto 1). Sin embargo, con el fin de optimizar el hallazgo de las estructuras exhumadas, el área de intervención se amplió durante el proceso de excavación por el lado norte $(1,10 \mathrm{~m}$. por $3,80 \mathrm{~m}$.) y oeste $(1,30 \mathrm{~m}$. por $4 \mathrm{~m}$.). Finalmente, la zona excavada contó con una superficie 
total de $31,88 \mathrm{~m}^{2}$ y una potencia estratigráfica de algo más de $2 \mathrm{~m}$, donde se individualizaron un total de veintitrés unidades estratigráficas.

\section{1. Horizonte de ocupación contemporáneo}

Después de efectuar las pertinentes labores de limpieza y marcar la superficie de intervención (U. E. 1), se retiró un primer estrato de tierra muy heterogéneo y de escasa compactación (U. E. 2). Se trataba de un nivel superficial de textura arcillosa y suelta, de color marrón claro, con una potencia de entre 0,05 m. y 0,20 $\mathrm{m}$, que cuenta con inclusiones de teja, gravilla, piedra y un entramado de raíces de la vegetación superficial que ocupaba toda la superficie del sector (PLANO 1) (FOTO 2).

En el cuadrante norte del sondeo se exhumaron los restos de una presumible canalización (U. E. 5) destinada a evacuar las aguas del interior del castillo. Estaba formada por tres tejas curvas de gran formato, superpuestas entre sí, y con orientación oeste-este (Foto 3). Dicha canalización era visible también en el testigo de seguridad del perfil occidental y se introducía en el sondeo por su flanco noroeste, presentando una leve inclinación hacia el lado este. Las medidas de la parte de canalización que se sacaron a la luz eran de 0,50 m. de ancho por 1, $66 \mathrm{~m}$. de longitud (PLANO 1).

Debemos tener en cuenta que su extremo oriental estaba fragmentado y, en cuanto a su función, sería la de un albañal que facilitase la salida de aguas del interior de la fortaleza. Para su construcción se realizó una zanja de cimentación (U. E. 7) con forma de "U". Se erigió mediante el uso de grandes losas de pizarra local en la base y pequeños bloques de piedra de cuarzo trabados con tierra para los laterales. Una vez en desuso, esta canalización se amortizó con tierra arcilloarenosa (U. E. 6) de granulometría media, fina y suelta. Según distintas fuentes orales, dicha canalización fue realizada a principios de siglo pasado, coincidiendo con el uso del castillo como majada de ganado ovino (PLANO 7).

En esta fase encontramos también una acumulación de piedras (U. E. 8) de distintos tamaños y sin orden aparente, situadas en la parte central de sector. Ocupan una superficie aproximada de $2,5 \mathrm{~m}$. por $1,15 \mathrm{~m}$. Al respecto, hemos de tener en cuenta que las fuentes orales aluden a la venta que, hace unas cuantas décadas, el antiguo propietario del castillo hizo de una parte de las piedras procedentes, sobre todo, de la parte superior de la muralla. Estas parece que eran trabajadas en la zona donde se localizó la referida concentración (PLANO 1). Por ello, barajamos la posibilidad de que U. E. 8 pueda corresponder a los desbroces de las mismas (FOTO 4). Además, este tipo de acumulación, sin orden aparente, se evidenció también en el interior del castillo (PLANO 7). 
En la zona central del cuadrante noroeste, entre las UU. EE. 5 y 8 se excavó un nivel de tierra de textura arcillosa y color marrón claro (U. E. 11). Presentaba una potencia de aproximadamente $1 \mathrm{~m}$. y englobados en su matriz aparecieron diversos fragmentos de teja curva, ladrillo, algunos bloques de piedra caliza y cuarzo de pequeño tamaño, además de restos de carbones vegetales. Este estrato desarrollaba una clara tendencia vertical y su formación podría estar relacionada con un vertido o echadizo efectuado en esta área (PLANO 7).

A la fase contemporánea pertenecen también una serie de sedimentos de diferente composición, que se caracterizan por presentar disposición horizontal y estar ligeramente basculados hacia el sureste. Los dos primeros estratos (UU. EE. 14 y 15) son de color marrón, textura arcillosa y cuentan con abundantes inclusiones de cantos rodados, lajas de pizarra y piedras de cuarcita y caliza de reducidas dimensiones. $\mathrm{Su}$ potencia oscilaba entre $\operatorname{los} 0,15 \mathrm{~m}$. y $0,25 \mathrm{~m}$. y sobre ellos estaba dispuesta la acumulación de piedras U. E. 8. Estos estratos fueron interpretados como posibles capas de nivelación del suelo (PLANO 7).

El estrato inmediatamente inferior (U. E. 16) estaba constituido por una arcilla de color rojiza de textura suelta, muy homogénea. Estratigráficamente le sigue la U. E. 17, situado en un nivel inferior al anterior, y formada por restos de ceniza y sedimentos arcillosos de color rojizo resultante de la acción continuada del fuego. Ambas unidades poseen una potencia de entre $0,10 \mathrm{~m}$. y $0,12 \mathrm{~m}$, con una clara horizontalidad y un leve buzamiento hacia el perfil meridional. Se trataría de dos niveles de destrucción y/o abandono (PLANO 7).

Por último, aludiremos a las dos unidades estratigráficas resultantes de las recientes obras de construcción del alcantarillado y acondicionamiento de la acera realizadas en el entrono de la fortaleza. Por un lado, la U. E. 20 consistente en un vertido, de unos $0,70 \mathrm{~m}$. de potencia, que se localiza entre la acera, la canalización y el antemuro identificados en el perfil noreste del sondeo. Se trata de una capa de tierra de color marrón claro, textura areno-arcillosa y baja compacidad, con inclusiones de grava, material constructivo y adobe, además de plásticos y cascotes de vidrio. También en este relleno se evidenció una mancha de adobe (U. E. 21) de color amarillento, textura arcillosa y muy compacta, que medía unos 0,30 m. por 0,50 m. Dicha mancha estaba situada junto a la cara exterior del cimiento U. E. 3 . La segunda unidad, corresponde a un pavimento de adoquines aunados con hormigón (U. E. 23). Este pavimento sirvió a su vez de límite en la ampliación que se hizo del sondeo, quedando así reflejado en el perfil norte (PLANOS 3 y 4). 


\section{2. Fase de Época Moderna}

En primer lugar, debemos tener en cuanto que no existe ninguna evidencia arquitectónica perteneciente a este periodo cronológico, únicamente tenemos constancia de un nivel arqueológico de grandes dimensiones, exhumado en el cuadrante noroeste y sureste del sector (U. E. 19), consistente en un gran depósito de tierra arcillosa de granulometría media y baja. Este estrato contiene inclusiones de material constructivo, gránulos de mortero de cal, esquirlas y fragmentos de piedras cuarcíticas y restos de carbón vegetal con una potencia de unos $1,70 \mathrm{~m}$. cuya situación estratigráfica y materiales recuperados (restos de cerámica y fauna doméstica) nos inducen a datarlo con posterioridad a la utilización de las estructuras defensivas del exterior del castillo. Contenido en este estrato (U. E. 19) se halló una bolsada de fragmentos de pizarra (U. E. 12), con un espesor de entre 0,20 m. y 0,80 m. (Planos 3-5).

\section{3 Horizonte moderno/bajomedieval}

En este horizonte se exhumaron una serie de elementos arquitectónicos, destacando el cimiento (U. E. 3), identificado como el posible antemuro de la fortaleza con un uso sin duda defensivo (FOTOS 5 y 6 ).

$\mathrm{Su}$ aparejo es de mampostería trabado con argamasa a dos caras vistas -la exterior de mejor factura que la interior-. Para su construcción se emplearon bloques de cuarcita de mediano tamaño, unos trabajados y otros sin trabajar, formando así hasta quince hiladas que se caracteriza por su irregularidad. Presenta una orientación sureste-noroeste y discurre en paralelo al lienzo oriental de la muralla. La parte del presumible antemuro que se sacó a la luz mide unos 1,80 m. de ancho por 1,30 m. de alto y unos 7, $5 \mathrm{~m}$. de largo (Planos 2 y 6).

Además, se localizó la zarpa de cimentación (U. E. 13), visible únicamente en el extremo norte de su cara exterior. Esta se erigió también a base de bloques de cuarcita de mediano tamaño, trabados con argamasa. Por el extremo norte se introduce por debajo del mencionado enlosado de adoquines construido recientemente (U. E. 23), mientras que por el suroeste penetra en el perfil. A su vez, asienta sobre un nivel de relleno situado al interior del foso (U. E. 22) (PLANOS 3 y 4).

Otra de las estructuras identificadas en este horizonte cronológico es una canalización (U. E. 4) formada por lajas de pizarra y bloques de cuarcita trabados con un mortero de cal y arena (FOTOS 7 y 8). Cuenta con una orientación suroestenoreste, discurre en perpendicular a la puerta de acceso al castillo y tiene una leve caída hacia el este. Los restos de la canalización que sacamos a la luz miden 
aproximadamente $1 \mathrm{~m}$. de ancho, 3,10 m. de largo y 0,80 m. de alto (PLANO 2). Su función sería la de evacuar las aguas residuales del interior de la fortaleza. Además, debemos añadir que parece coetánea al posible antemuro, dado que dicha canalización aparece atravesándolo en su interior de oeste a este. Tal y como mencionamos más arriba, parte de esta estructura fue localizada ya en un sondeo que la arqueóloga González Fernández realizó al interior del castillo en el año $2004^{24}$.

El sustrato geológico (U. E. 18) está constituido por tierra de color rojizo, de textura arcillo-arenosa y compacta, con intrusiones de grava natural y canto rodado. Además, presenta una leve inclinación hacia el sur y el este, constatada en toda la superficie intervenida (PLANOS 3-7). Pendiente que se evidencia en toda la comarca de Jamuz, lo que se explica por estar emplazada en la terraza fluvial del margen izquierdo del río Órbigo ${ }^{25}$.

Seguidamente, se pusieron al descubierto dos estructuras practicadas en el propio nivel geológico. La primera corresponde una superficie horizontal (U. E. 9) localizada en el cuadrante suroeste del sector, que mide unos 4,90 m. por 1,08 m. Se trata de un nivel de circulación realizado en el sustrato natural y conformado por una tierra arcillosa con intrusiones de grava muy compacta y de color rojo (Foto 9). La U. E. 9 se interpreta como la posible berma o pasillo de la fortaleza, la cual se localizó asimismo al norte del paramento oriental de la muralla durante la excavación llevada a cabo en el año 2009 (PLANOS 2, 5 y 7).

La segunda estructura corresponde a una gran trinchera excavada en el sustrato geológico, que cuenta con un pronunciado talud y es plana en la base (U. E. 10) (FOTO 10). Tiene una profundidad de aproximadamente $2 \mathrm{~m}$. y orientación surestenoroeste. La U. E. 10 arranca del flanco occidental de la berma (U. E. 9) y discurre en paralelo a la línea de muralla del castillo (PLANOS 2 y 7) (FOTOS 11 y 12). Dicha trinchera se interpreta como el foso defensivo de la fortaleza, que fue hallado también en una intervención previa realizada por la empresa TALACTOR en al año 2009 en dos $\operatorname{sondeos}^{26}$. En el primer sondeo de $7 \mathrm{~m}$. de largo por $3 \mathrm{~m}$. de ancho,

24 GONZÁlez FERNÁNDEZ, Mª L. (2004). Excavación, seguimiento y/o documentación arqueológica en las obras de rehabilitación parcial del castillo de Villanueva de Jamuz. León: Informe inédito depositado en el Servicio Territorial de Cultura de León, Junta de Castilla y León.

${ }^{25}$ Alonso HerRero, E. (2004). Guía geológica de la provincia de León. León: Celarayn.

26 SAN ROMÁN FERNÁNDEZ, F, CAMPOMANES ALVAREDO, E. y MuÑOZ Villarejo, F. (2009). Informe preliminar excavación arqueológico castillo de Villanueva de Jamuz, Santa Elena de Jamuz. (León). León: Informe inédito depositado en el Servicio Territorial de Cultura de León, Junta de Castilla y León. 
practicado en el lateral este del castillo, se localizó el foso del castillo, así como la berma, de unos 4,5 m. de anchura. Mientras que el segundo, con $6 \mathrm{~m}$. de longitud por $3 \mathrm{~m}$. de anchura, realizado en el lateral norte del mismo se pudo identificar también el foso, aunque en este caso surge desde el pie de la misma muralla de la fortaleza y no aparece la berma.

Parece que, una vez en desuso, el foso fue amortizado en su cota inferior por un nivel terrero (U. E. 22), coincidiendo en el tiempo con la construcción del antemuro. Esta U. E. 22 estaba conformado por una tierra de textura arcillosa, de color verdoso, con granulometría media e inclusiones de teja, ladrillo, cantos cuarcíticos y restos de carbón vegetal. Posee una potencia de $0,60 \mathrm{~m}$. y albergaba una serie de fragmentos de cerámica, metal, restos constructivos y macrofauna (PLANOS 3 y 4) (FOTOS 13 y 14).

\section{ANÁLISIS DEL MATERIAL ARQUEOLÓGICO}

Las cerámicas localizadas en el castillo de Villanueva de Jamuz datan, fundamentalmente, de época Bajomedieval y Moderna. Estos recipientes se realizan con rocas silíceas, de tonos rojizos y de textura poco compacta. En ellas se aprecian algunos desgrasantes de entre 0,5 y $2 \mathrm{~mm}$, de composición heterogénea y entre las que destaca la presencia de cuarzo, mica, etc.

La técnica de fabricación empleada a la hora de modelar las arcillas es el torno rápido. En su mayor parte, estas piezas han sido sometidas a ambientes de cocción oxidantes o alternos.

Desde el punto de vista morfológico, se identifica un reducido reportorio formal, destacando la presencia del tipo jarra (FIGURA 1), cuenco (FIGURA 2), cazuelas, plato/fuente y cántaro. En cuanto a los motivos decorativos, se identifican únicamente líneas incisas, bruñidos, acanaladuras y algún ejemplar vidriado.

Este tipo de producciones parecen proceder de la cercana localidad de Jiménez de Jamuz. Se trata de un centro de actividad alfarera con una larga tradición histórica que, de hecho, se mantiene en activo en la actualidad. Si atendemos a los testimonios documentales, tenemos conocimiento de esta actividad en la zona, al menos, desde comienzos de la época Moderna, si bien no sería descabellado remitirnos a orígenes anteriores ${ }^{27}$. En la misma secuencia ocupacional se sacaron a la luz dos pequeños ejemplares de agujas de metal (FIGURAS 3 y 4).

\footnotetext{
${ }^{27}$ KoPER, W. (1981). Guía de los alfares de España. Madrid: Editora Nacional; BRANDO, M. y GONZÁLEZ, J. L. (1990). Alfarería popular leonesa. León: Diputación Provincial de León; MARTínEZ,
} 
Por otro lado, entre los restos materiales exhumados en la excavación a su vez debemos aludir a los abundantes fragmentos de fauna encontrados en los niveles más superficiales. Junto a ésta, se localizaron varios restos de objetos de metal y vidrio también de época Contemporánea, así como materiales de construcción ladrillos, tejas, etc.--

\section{INTERPRETACIÓN DE LOS RESTOS Y CONCLUSIONES}

La actuación arqueológica realizada frente a la actual puerta de acceso a la fortaleza, donde afloraban en superficie restos visibles de construcciones, pusieron al descubierto diversas estructuras relacionadas con la defensa y protección de la puerta principal de la fortaleza como el antemuro, el foso y la berma, así como una acometida de saneamiento de aguas.

El nivel natural está definido por un sustrato de grava y arcilla de tono rojizo muy compacto. En dicho nivel, junto al ángulo S.W. del sondeo, se halló una superficie horizontal que hemos identificado como la berma del castillo. Del límite oriental de esta superficie arrancaba el foso o trinchera con un pronunciado talud y con una profundidad de $2 \mathrm{~m}$. Lo cierto es que no hemos podido determinar ni la anchura de la base, ni de la totalidad del foso ya que su extremo E. se encuentra fuera de los límites del área excavada. Esta trinchera se colmata con un nivel de tierra de textura arcillosa y color verdoso que proporcionó escaso material arqueológico (tejas, ladrillos, piedra local, microfauna, fragmentos de bronce y restos de cerámica tardomedieval y moderna).

Desde un punto de vista cronológico, tanto el foso como la berma parecen haberse construido en los mismos momentos que el recinto fortificado con el objetivo de proteger el principal acceso del castillo.

$\mathrm{Al}$ interior del foso y sobre el mencionado relleno, se levantó en un momento posterior una estructura mural de carácter defensivo que, debido a su ubicación y potente cimentación, se podría identificar como la barrera artillera o antemuro de la fortaleza y que se asemeja a la conservada en enclaves próximos como son los de Valencia de don Juan ${ }^{28}$ o el castillo de Benar (Riello) ${ }^{29}$. Esta construcción conserva

R. (2006). «El centro alfarero de Jiménez de Jamuz. Estudio histórico y etno-arqueológico». Estudios Humanísticos, 5, pp. 309-332.

${ }^{28}$ GutiÉRREZ, J. A. y BENÉITEZ, C. (1997). «Aportaciones al repertorio cerámico bajomedieval castellano: las producciones de Valencia de don Juan». La céramique médiévale en Méditerraneé. Actes du 6 congrés, Aix-en-Provence. Aix-en-Provence: Narration Éditions, pp. 539-548.

${ }^{29}$ Cobos Guerra, F. y Retuerce Velasco, M. (2011). Metodología, valoración y criterios de intervención en la arquitectura fortificada de Castilla y León. Cátalogo de las provincias de León, 
unas medidas de $1,80 \mathrm{~m}$. de ancho, $1,50 \mathrm{~m}$. de alto y una longitud de aproximadamente $5 \mathrm{~m}$. Se erigió con piedra caliza trabada con argamasa y presenta una orientación N.W-S.E, discurriendo pues en paralelo al lienzo oriental de la muralla de la fortificación. Además, el paramento al interior es de peor factura que al externo, siendo este último un aparejo a soga y tizón.

También, se observa como el extremo N.W. del cimiento se introduce bajo el adoquinado del entorno del castillo, al tiempo que en el extremo S. E. se aprecian claras evidencias tanto de saqueo de la piedra, como de la destrucción provocada por las construcciones posteriores. La estructura señalada se erigió, a buen seguro, como una necesaria adaptación pirobalística a fin de protegerse de un hipotético ataque artillero, por lo que debe encuadrarse cronológicamente durante la Baja Edad Media o a comienzos de la Época Moderna, coincidiendo con el abierto enfrentamiento de los Quiñones con los Condes de Luna por el control de este territorio y de los que ya hemos hecho referencia. Teniendo en cuenta, además, que los flancos septentrional, oriental y occidental del castillo no cuentan con ningún tipo de protección natural, es muy posible que dicho muro se extendiera a lo largo de todo su perímetro exterior y no solamente en la vertiente excavada.

Coetánea al antemuro, se exhumó parte de una atarjea utilizada para evacuar las aguas residuales procedentes del interior del castillo y que evidencia claramente el uso de sus instalaciones también como vivienda. Se dispone en perpendicular a la puerta de acceso y cuenta con una orientación W-E, con una leve inclinación hacia el E. Dicha canalización está contenida en el propio antemuro y, de hecho, lo atraviesa en sentido W-E.

Entre las estructuras contemporáneas destaca una construcción hidráulica que consiste en una canalización de teja curva, identificada ya en el testigo de seguridad occidental. Esta discurre en sentido W-E, presentando una leve caída hacia el E. Se extiende perpendicular a la línea de fachada y tiene como función evacuar los residuos procedentes del interior del castillo cuando fue utilizado como majada de ganado ovino. Para calzar la tubería practicaron una zanja rellenada con piedra y pizarra y trabada con tierra.

Finalmente, el material arqueológico recuperado en los distintos niveles estratigráficos resulta más bien escaso, predominando fundamentalmente los fragmentos de cerámica de época Moderna y que posiblemente proceden de la

Salamanca, Valladolid y Zamora. Valladolid: Junta de Castilla y León, Consejería de Cultura y Turismo. 


\section{Raquel Martínez Peñín}

cercana población de Jiménez de Jamuz, así como de restos de material constructivo y la fauna.

\section{APÉNDICE GRÁFICO}

Mapa 1. Localización de la población de Villanueva de Jamuz, León

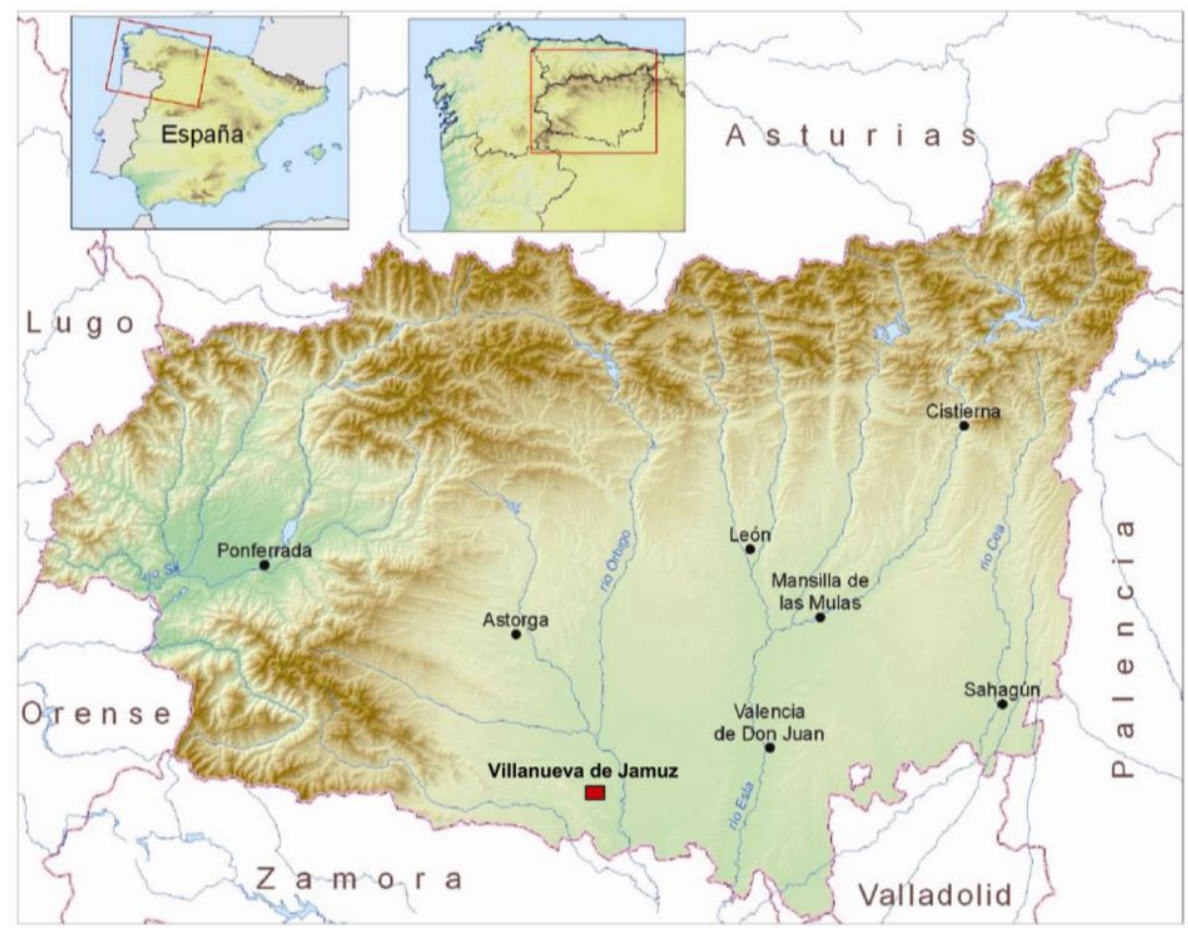


El castillo de Villanueva de Valdejamuz: una construcción defensiva en el marco de la...

Foto 1. Planteamiento del sondeo de excavación

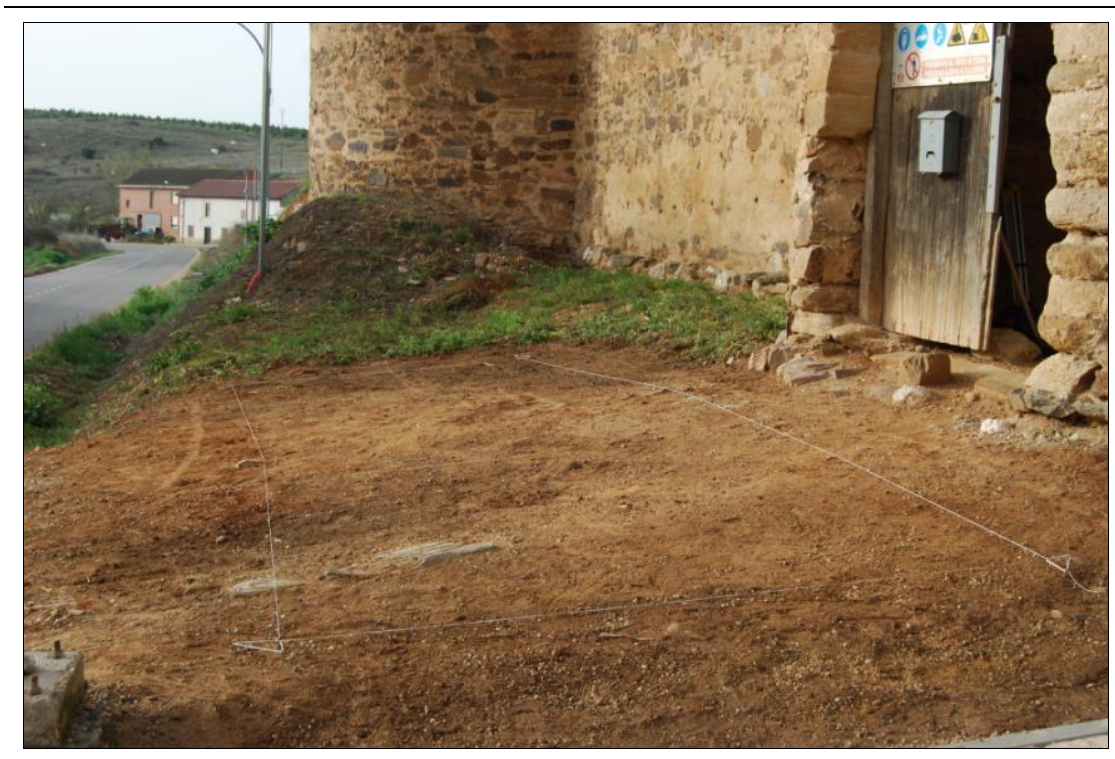

Foto 2. Antemuro de mampostería

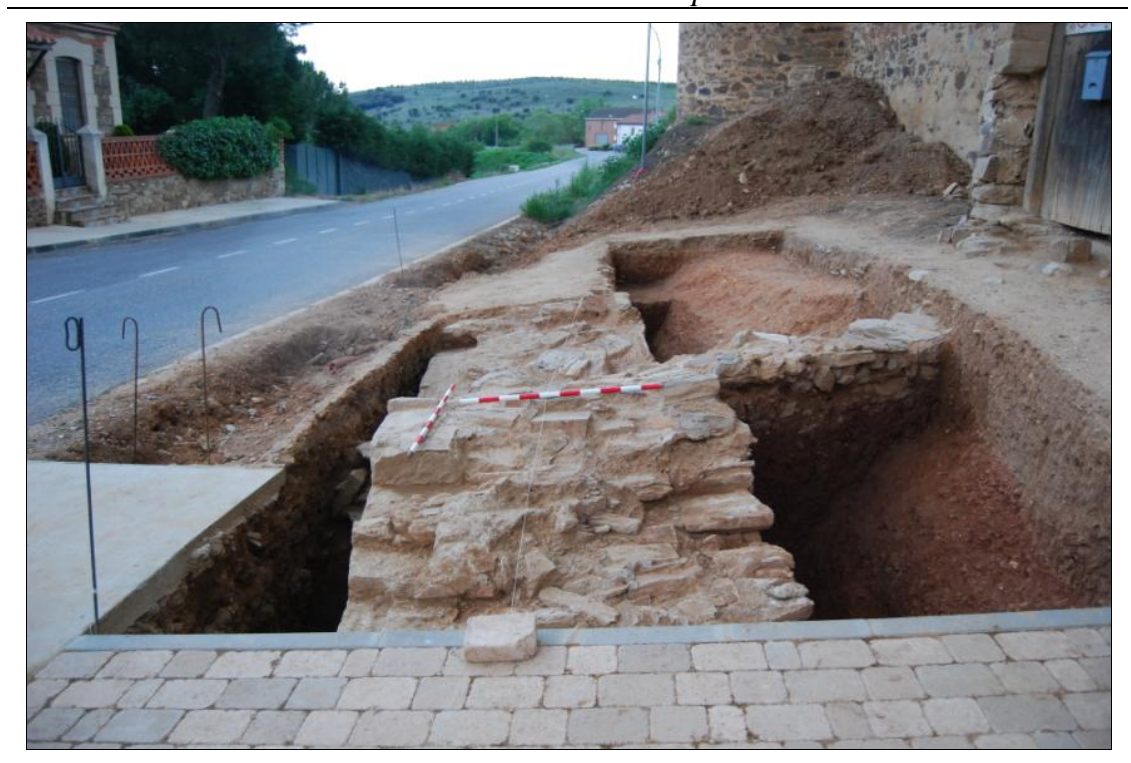




\section{Raquel Martínez Peñín}

Foto 3. Cara vista del antemuro

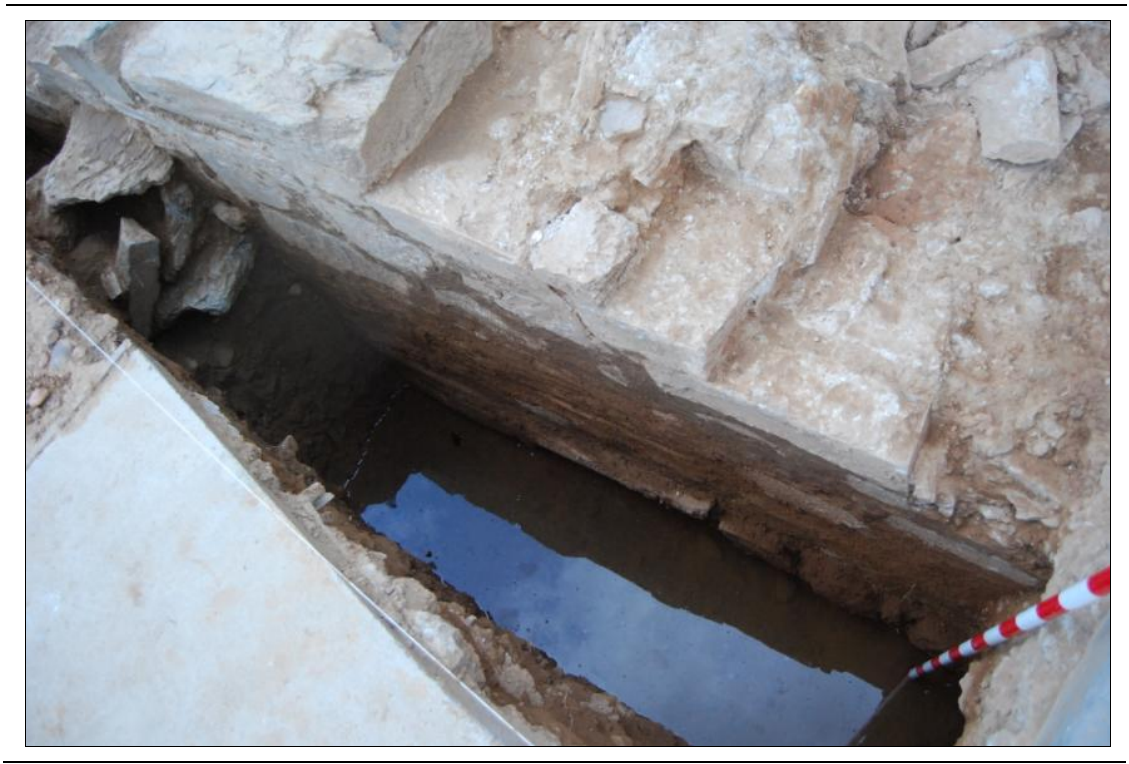

Foto 4. Atarje

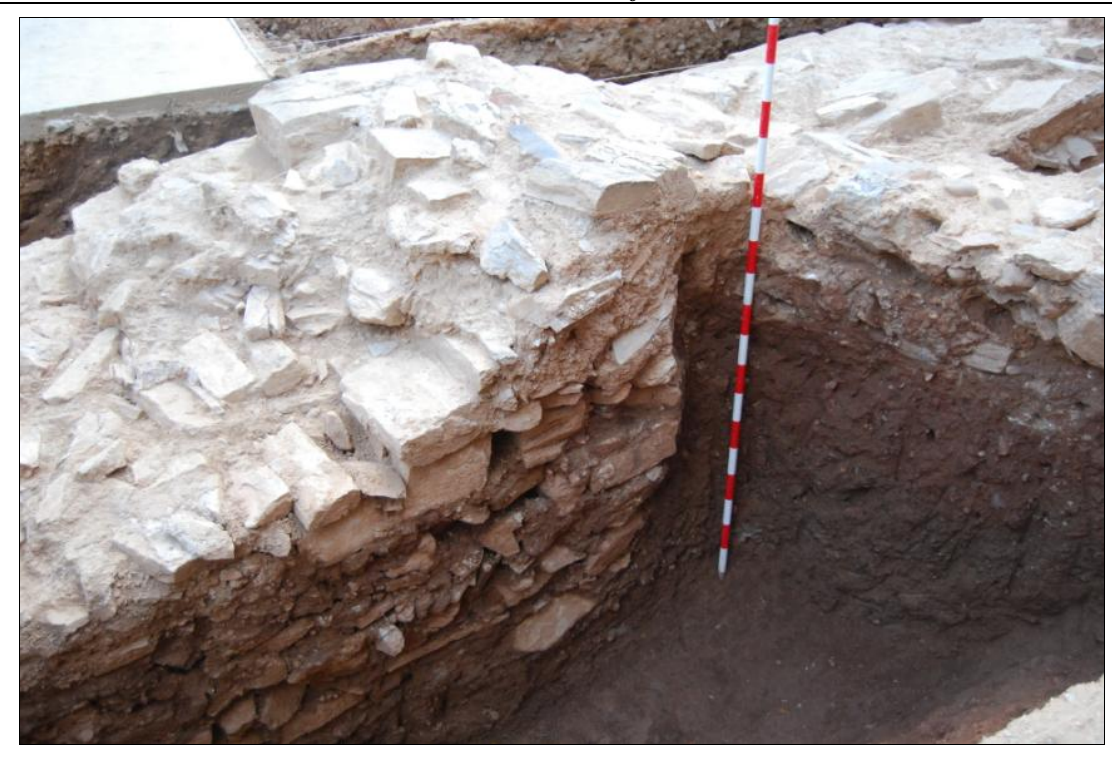


El castillo de Villanueva de Valdejamuz: una construcción defensiva en el marco de la...

Foto 5. Berma

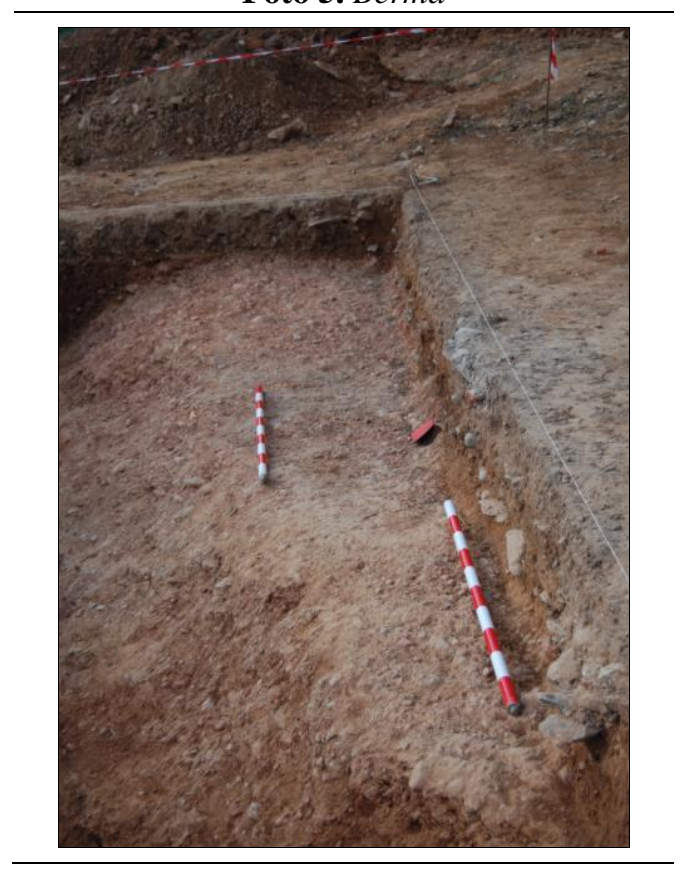

Foto 6. Emplazamiento del foso

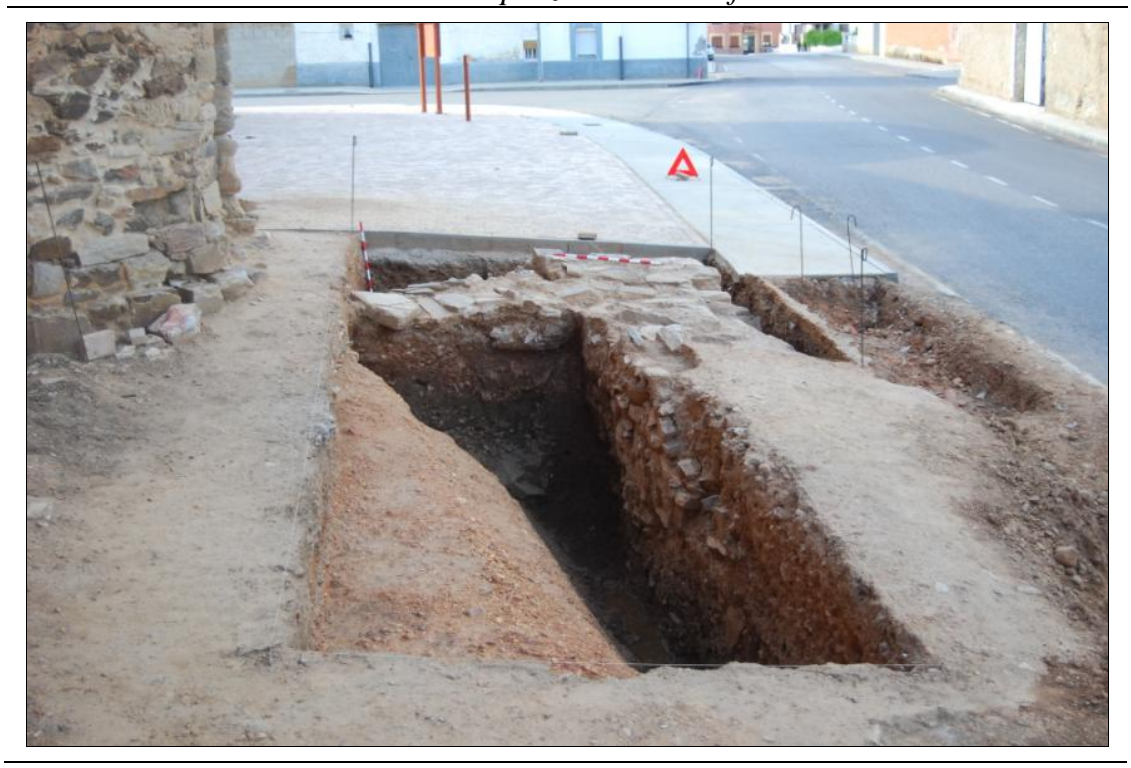




\section{Raquel Martínez Peñín}

Plano 1. Estructuras contemporáneas

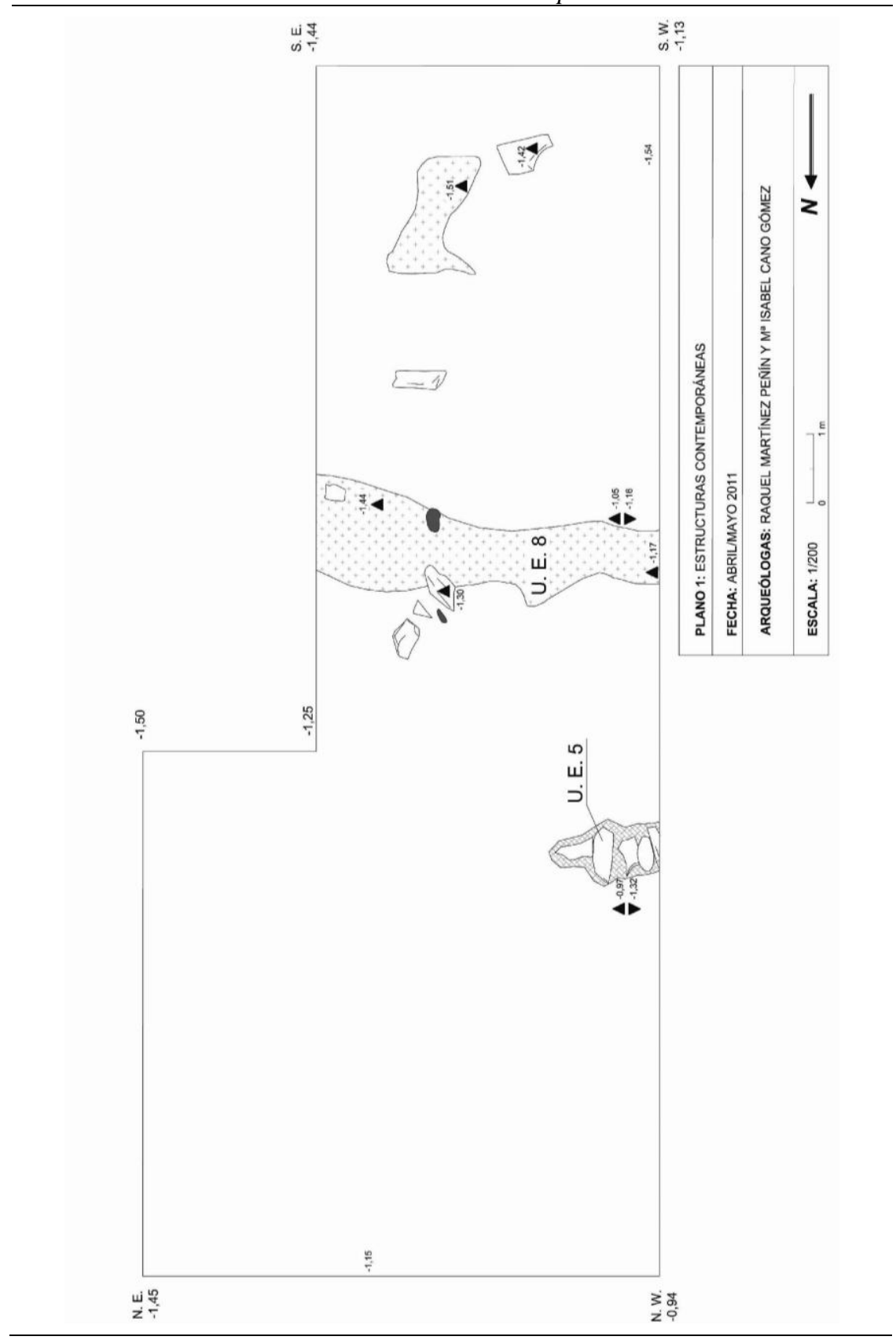


El castillo de Villanueva de Valdejamuz: una construcción defensiva en el marco de la...

Plano 2. Estructuras medievales/modernas

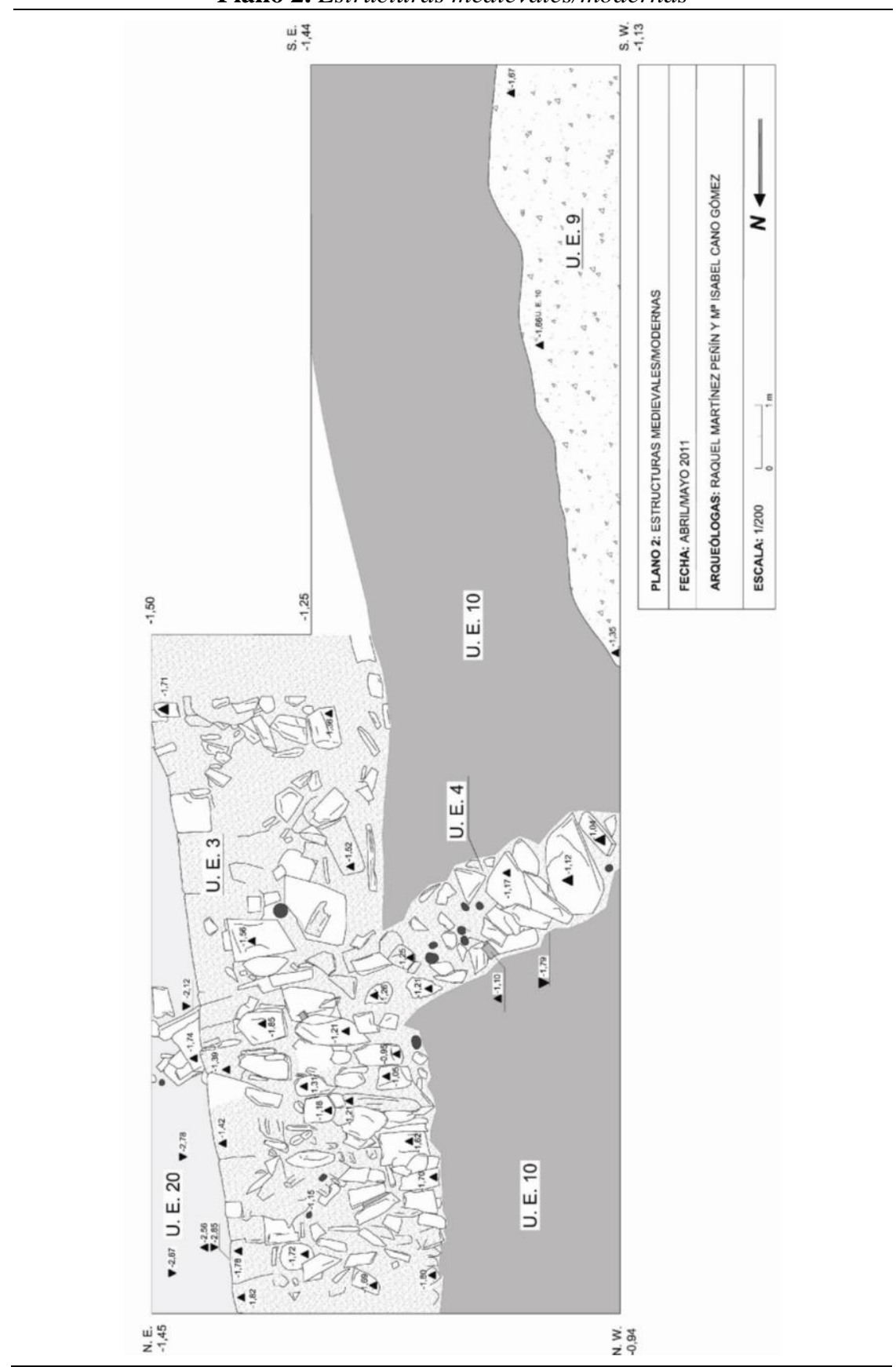


Raquel Martínez Peñín

Planos 3 y 4. Perfil norte

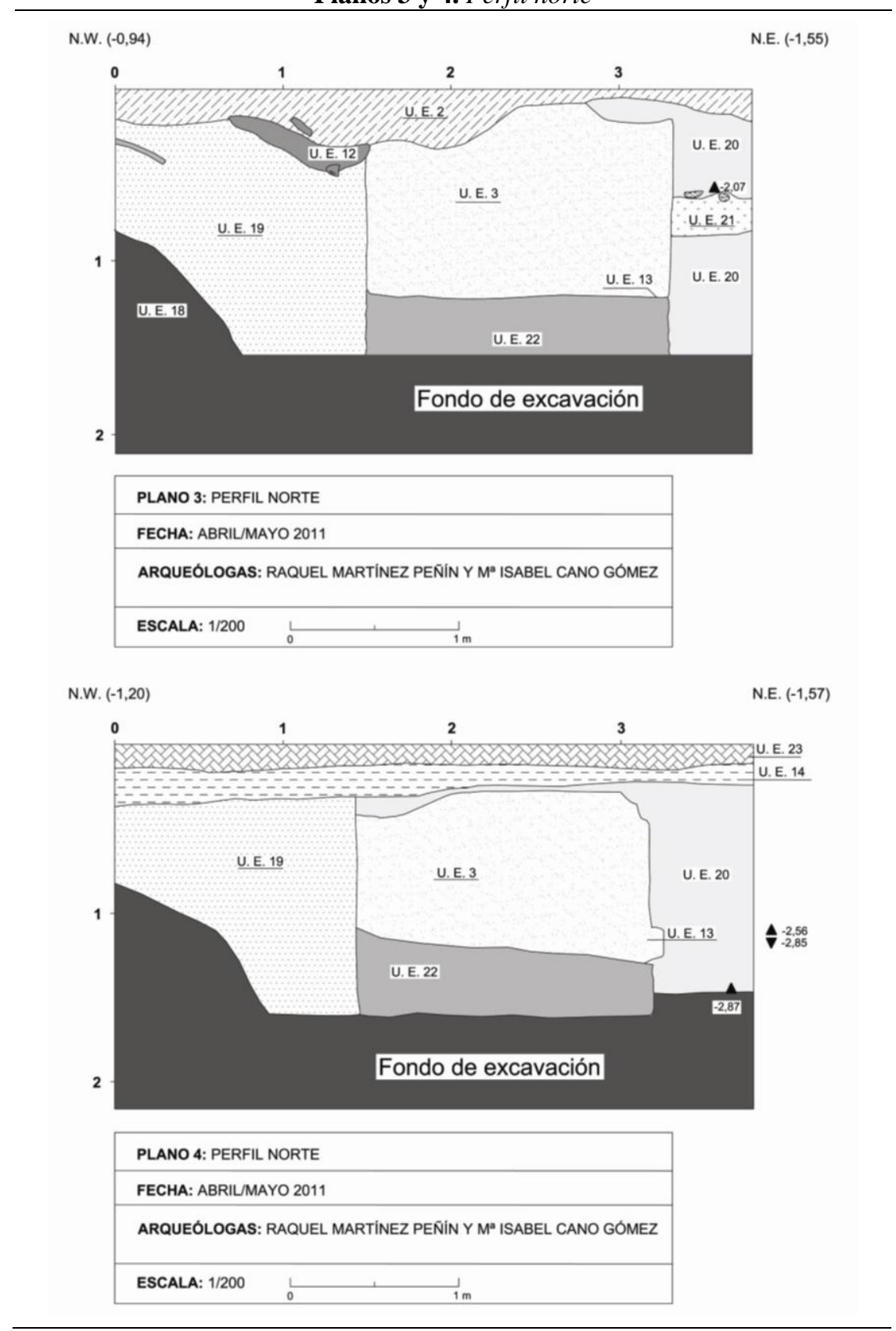


El castillo de Villanueva de Valdejamuz: una construcción defensiva en el marco de la...

Plano 5. Perfil sur

S.E. $(-1,44) \quad$ S.W. $(-1,13)$

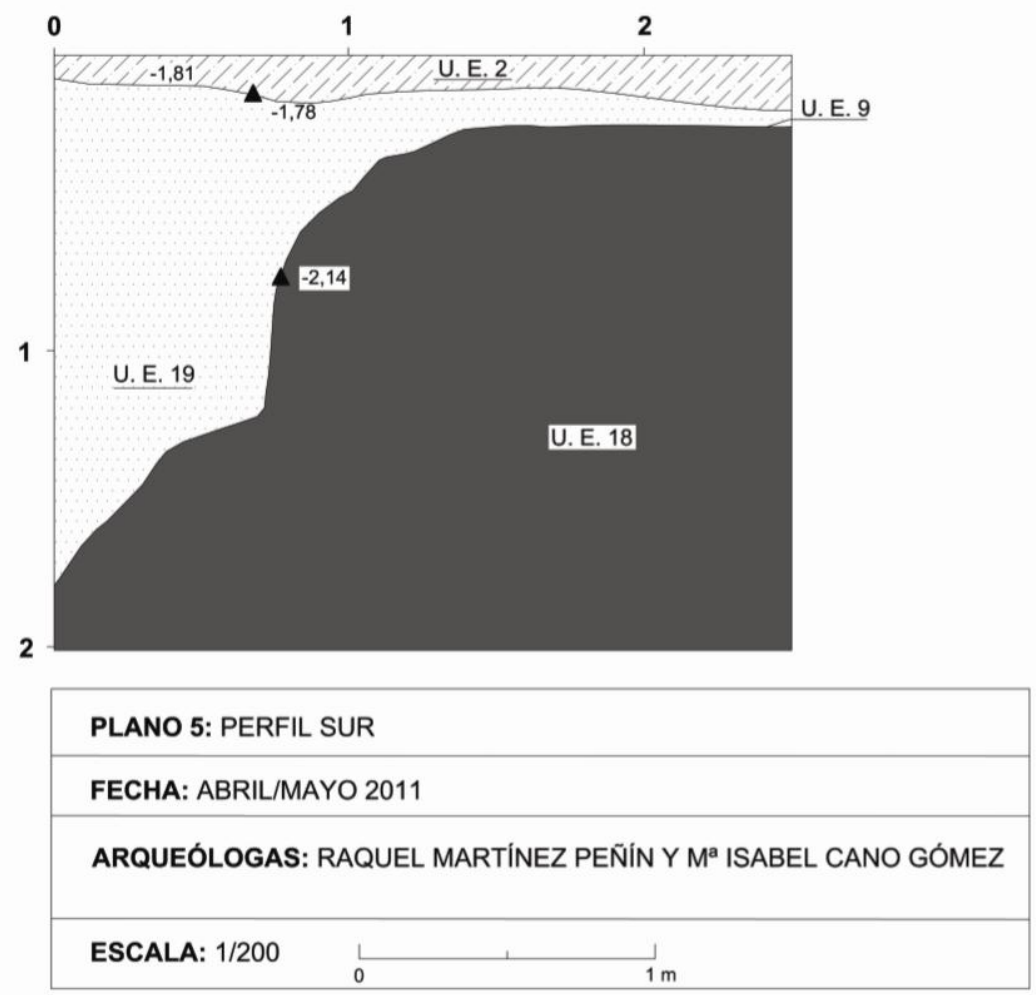


Raquel Martínez Peñín

Plano 6. Perfil este

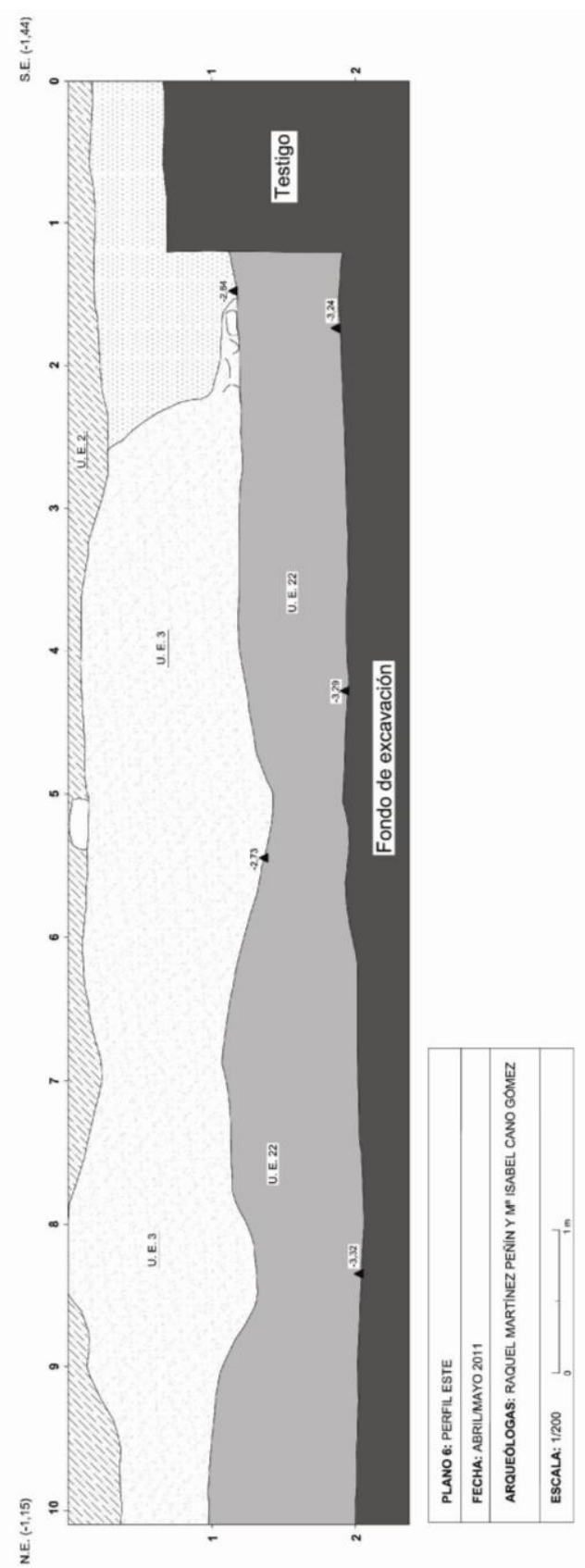


El castillo de Villanueva de Valdejamuz: una construcción defensiva en el marco de la...

Plano 7. Perfil oeste

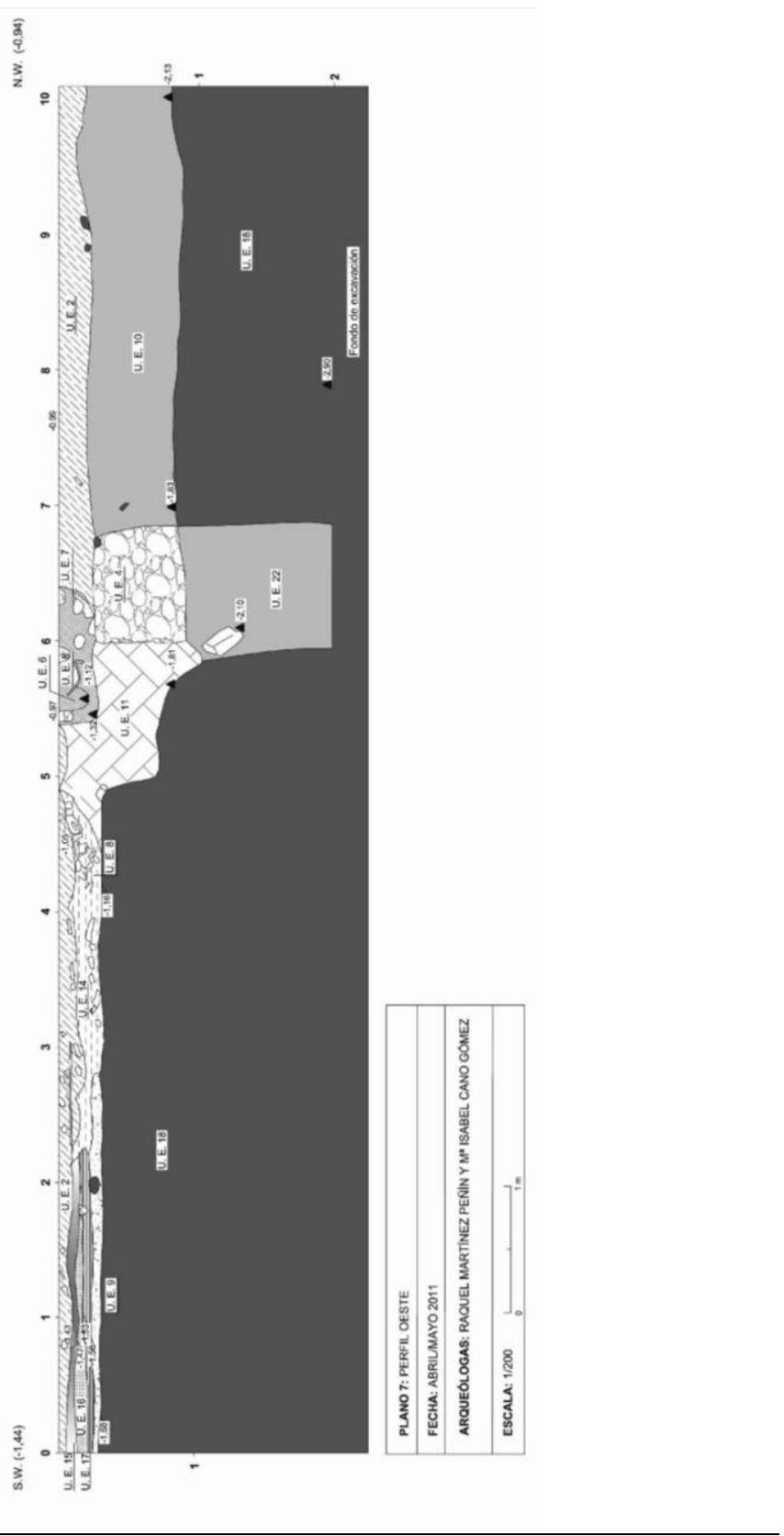


Raquel Martínez Peñín

Figura 1. Fragmento de jarra
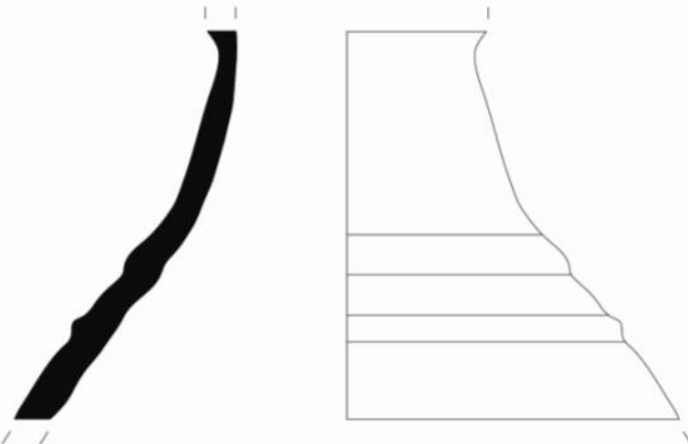

2011-10-19-32

0 $5 \mathrm{~cm}$

Figura 2. Perfil completo de cuenco

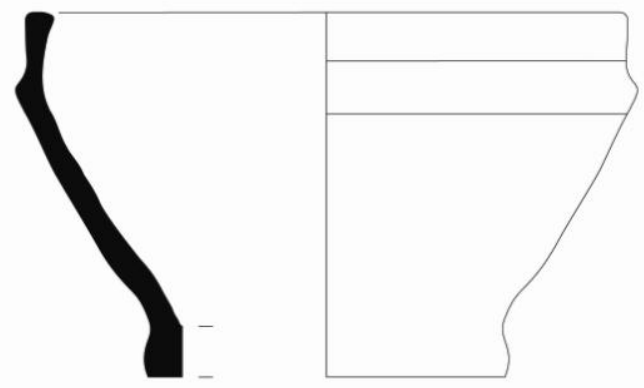

2011-10-19-71

0 $5 \mathrm{~cm}$ 


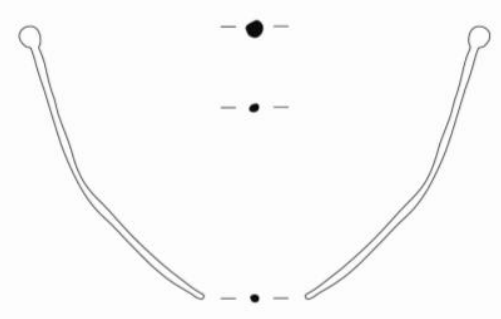

2011-10-19-80

0

Figura 4. Aguja de metal

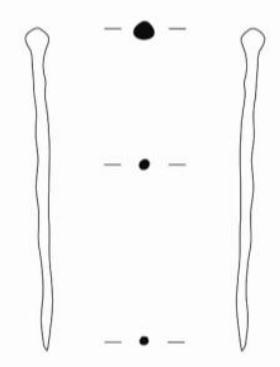

2011-10-16-21 
